\title{
The Influence of Intercultural Awareness on Acquisition of Linguistic Competence
}

\author{
Hongli Gao \\ Faculty of Humanities and Foreign Languages \\ Xi'an University of Technology, 710048 \\ Xi'an, China \\ Email: gaohl@xaut.edu.cn
}

\author{
Xianfeng Feng \\ School of Automation and Information Engineering \\ Xi'an University of Technology, 710048 \\ Xi'an, China
}

\begin{abstract}
The linguistic system is part of the social system. The learning of language and the learning of culture can be learned without the other. Therefore, this paper expounds and analyzes the basic opinions of culture and Intercultural communication, discloses the importance and necessity of intercultural awareness which exercises influence on acquisition of linguistic competence, through analyzing the benefits of intercultural awareness research in learning of language so as to promote intercultural communication and operate effectively in social context.
\end{abstract}

Keywords-intercultural awareness; Intercultural Communication; linguistic competence

\section{INTRODUCTION}

Modern society has made intercultural communication a necessity. With the world becoming smaller, many young people decide to seek their further education abroad. It is a new experience, which brings them the opportunity of discovering new things and learning new cultures. Besides, intercultural communication has been greatly enhanced with the mobility of people and the contact between countries. An increasing number of people are offered opportunities to learn new cultures and communicate each other. Intercultural communication meets the theirs' curiosity about the world which it will stimulate their desire for communication in English.

Despite these advantages, some problems and difficulties will arise when they are actually involved in intercultural communication. English, as an international language, has called for Chinese learners' intercultural awareness. It is believed If we have a good command of English, we will just familiar with all the grammar rules and have a large amount of vocabulary, along with much practice in drill of sentence patterns. People always assume that level of proficiency in English depends on degree of proficiency in grammar rules and the amount of vocabulary. Experience has shown, however, there really is no substitute for trying to know and acquaint English learners with English cultures that many learners can use the language in a relaxed atmosphere. Because it is really the challenge for people who live in a country where their target language is not spoken. For example, if someone says ' He go to work' instead of 'he goes to work', the grammatical mistake does not affect his communication with a native English speaker. However, if he asks an English lady how old she is no matter how correct his grammar and pronunciation might be the English lady may not be tolerant of his blunder, because such a question could put her in an embarrassing situation. This example shows that intercultural awareness is required if the foreign language learner is to gain the communicative ability, which is now commonly viewed as the objective of language learning.

\section{INTERCULTURAL AWARENESS}

Intercultural awareness becomes especially important when a learner reaches the advanced stage and reads authentic English texts. Very often familiarity with the dictionary definitions of lexical items and the mastery of sentence structures do not seem to be enough for the learner to understand the information. Each nation has its own conventions and cultures. Our culture influences who we are and our understanding of social behaviors. Communicating successfully with people from different cultures can be a real challenge because problems may occur when there exist cultural differences. People from different countries may choose different ways to deal with the same situations. Thus, sometimes misunderstanding arises. As language learners, we bear equal responsibility for teaching people of different cultures about our culture in turn learning about theirs. We cannot expect people from other cultures to understand our automatically. Probably the best strategy for coping with the various impacts of culture clash is to make a conscious effort to adjust to the new culture, though it may require everyone's cultural awareness, patience and perseverance.

When people from different cultures communicate, their respective "intuitive competence" may cause miscommunication. "Intuitive competence" is something native speakers possess, but foreign learners have to be trained in. Therefore, it becomes not only necessary but indispensable for Chinese students to increase the intercultural awareness in the English language learning.

To comprehend intercultural awareness, it is indispensable to for foreign language learners to understand what is meant by the term "culture". 


\section{CUlture}

\section{A. Language and its culture}

It is impossible for language learners to isolate our use of language and from our culture. Learning a foreign language well means more than mastering the pronunciation, grammar and expressions. It also means learning its culture. Language is the mirror of our cultural belief, and culture exerts the way we use language. People learn to reflect and act as they do because of the messages that have been communicated to them, and those messages all bear the mark of culture. The differences between languages are not only barriers to cultural communication; they often reflex more differences in the views of the different people and in what they know about their life and conditions. Therefore, the influence of culture becomes usual and general and makes life easier, just as breathing walking. Anthropologists define culture as any human behavior that is learned rather than genetically transmitted [1]. Whether Culture is high or not; it exists in any type or stage of civilization.

If we want to communicate in another language, it is crucial for language learners to know not only the rules of that language, but also the rules of culture.

\section{B. Culture is learned.}

Respect should be equally attached to every culture in the world. People learn about their culture through interactions with different people around them, and even strangers who are part of the culture. Culture is learned from those people with whom one interacts as he or she is socialized. Watching how adults react and talk to kids is an excellent place to see the actual symbolic transmission of culture among people. In the US, most children are asked, from a very early age, to make decisions about what they want to do and what they prefer; in many other cultures, a parent would never ask a child what he wants to do but would instead simply tell the child what to do. Culture is also taught by the explanations people receive for the natural and human events around them.

\section{Culture affects behavior.}

If culture is located in the minds of people, we could only speculate about what a culture is since it would be impossible for one person to see into the mind of another. However, the shared perceptions that characterize a culture give people guidelines about what things means, what is important, and what should or should not be done. Cultural differences can be noticed in the various ways in which people do their daily jobs. Culture comes down to a large number of people and groups. Unlike interpersonal a relationship which involves small groups of people, culture is used to refer to large groups of people. It refers to ethnicity, gender, profession, or any other symbol system that is bounded and prominent to individuals.

Culture molds rules, feelings, opinions, outlooks, ambitions, symbols, aspirations, insights and material properties. In turn, these interact culture, which means that cultures are varying, always living through huge variations. As individual and group qualities change, either due to the internal process of growth and maturation or contact with outside groups, cultures also change[2].

\section{INTERCULTURAL COMMUNICATION}

Culture is largely responsible for the construction of our individual social realities and for our individual repertories of communicative behaviors and meanings[3]. According to Hall, "A high-context communication or message is one in which most of the information is either in the physical context or internalized in the person, while very little is in the coded, explicit, transmitted parts of the message. A low-context communication is just the opposite.” [4]. He classifies cultures as being either high or low context, depending on the degree to which meaning stems from the contexts and settings for the words being interchanged.

Culture exerts profound effects on people in a decisive manner from birth to death and the effect is shown in every patterns of behavior and in communication practices. When cultures change, communication practices also. Intercultural communicators are concerned, chiefly, with the difficulties that can occur when cultural norms, values, and attitudes become in conflict and collision with one another. Language reflects our cultural priorities and values, and culture affects the way we use language.

Verbal communication is one of the most important parts in intercultural studies. What makes a conversation cozy, free and enjoyable differs widely from culture to culture. What is natural or normal in one culture can be uncomfortable and embarrassing in another. The importance of verbal communication seems to be universally acknowledged, but cultures differ in the importance they place on words talk and context. Our communication with people who have a diverse language and rules of verbal behavior may give rise to misunderstandings if we suppose their system of culture is the same as ours.

Nonverbal communication is usually considered as the process of communication through sending and receiving wordless message. It is estimated that the information conveyed by verbal codes in the communication account for $35 \%$ while information conveyed by nonverbal codes amounts to $65 \%$ [5]. Some nonverbal differences exist cross cultures and they may greatly influence intercultural communication. The same nonverbal action can be perceived and understood differently in different cultures.

As people are driven toward a global village and confronted with increasing frequent intercultural encounters, it is necessary to build up their intercultural awareness and sensitivity. It is becoming increasingly important for all the people to have the ability to communicate effectively with people from other cultures in the world, which is the top priority of intercultural communication.

In order to learn intercultural communication, foreign language learners may acquire the knowledge through classroom training and gain insight into culture which can be gained by extended experience which involves the difficulty of intercultural communication studies. To achieve better communication effects with people from different cultures, we have to know ourselves. We should understand our own culture and then better understand different cultures from other countries. 


\section{APPROACHES TO LEARNING INTERCULTURAL COMMUNICATION}

Intercultural communication studies are inter-disciplinary, deriving from anthropology, sociolinguistics and pragmatics. A word must be put in about the terms "inter-cultural" and "cross-cultural" since their Chinese equivalents seem to be the same. For most people, these two terms are interchangeable. Their use mainly depends on persona; preference. However, Gudykunst and Kim (1984) offered an explanation. They maintain that "intercultural" refers to "a comparison of some phenomena across cultures" They added, "The study of IC is generally considered to include cross-cultural communication" [6] .

The scope of "intercultural communication studies" is suggested by the name of the discipline: the study of communication-both verbal and nonverbal-between members of different cultures. In order to achieve successful intercultural communication, we should find out not only cultural differences, but also cultural similarities. For understanding differences will help us know where communication barriers lie; understanding similarities will help us get closer.

There are hundreds of approaches to learning the target culture, which depend on different conceptions and different goals. But generally speaking, these approaches may roughly be divided into two categories: intellectual approach (classroom knowledge) and experiential approach. There is no doubt that culture could be understood in no other way than by prolonged experience. Therefore, for learners of English as a foreign language, the best way to learn the target culture is to experience it. It is only through experience that we can really find out how native speakers use their language. However, it might be impossible for most EFL learners to go to the target country to learn the first-hand information. In that case, intellectual knowledge gained through classroom training, though somewhat incomplete, is the only alternative to throw the learners into the social and cultural milieu of the target language. We must not overlook the importance of intellectual knowledge and must make full use of every access we can obtain to the target culture: opening courses on intercultural communication studies, reading newspapers and magazines, watching movies and TV programmers of English-speaking countries, communicating with native speakers on the internet, etc. If we learn conscientiously, there still stands a good chance of learning the target culture. A successful learner is one who is a sharp observer, conscientious in learning. Here are a few points for students to keep in mind when they do a research on intercultural communication. Because of the complexities of culture, students should first of all select a subject, for example, verbal or nonverbal, or to be more specific, request or offering service, as one's focus in the research. In the intercultural communication studies, it is very important to collect data. It is very helpful to carry a notebook and jot down your experiences and observations, small as they might be, in daily life. Students should not stop at collecting a lot data. It is advisable to classify their data according to different subjects. Then they should go beyond the superficial phenomena into the deeper structure to find out explanations for certain behaviors in a particular culture. Facts and statistics speak louder than subjective comments.

\section{CONCLUSION}

Cultivating intercultural awareness usually comes along with learning a new language and being acquainted with a new culture. Intercultural awareness means developing the ability to understand cultures. Intercultural communication studies involve a variety of factors and are relatively a new field. Today, the importance of intercultural awareness in English learning has been widely recognized and intercultural communication as a discipline has been well established. During the process of English teaching, more weight should be attached to the introduction of cultural background, which may help the students to understand the use of language. Learning another language gives students insights into another culture and they can bridge the gap between their language and culture and others. All cultures have to change, but not to change by blending with mingling with one another or overwhelmed by a single culture. Each culture must change to the extent necessary for it to recognize difference, to acknowledge the diversity of other cultures, to find out some common ground upon which a talk about intercultural understanding and cooperation can be established. The research in this field is gaining its momentum all over the world. However, the road to finding the underwater part of this iceberg remains long.

\section{REFERENCES}

[1] Kramsch, Claire. 1996: Context and Culture in Language Teaching. Shanghai: Shanghai Foreign Language Education Press

[2] Gregg, J. Y. 1998: Communication and Culture: A Reading-writing Text Heinle and Heinle Publishers

[3] Yang Chunhua. 2005: A study of Devolopent Student's Cross-Cultural Communicative Competence in Chinese College English Teaching. Master's Thesis of Shandong Normal University

[4] Hall, E.T. 1959: The Silent Language. New York: Doubleday\&Co.

[5] B.M Grant \& Hennings,D.G. The Teacher Move: An Analysis of Non-verbal Activity. New York: Teachers College Press, 1971

[6] Gudykunst W. B.1992: Communicating With Strangers: An Approach to Intercultural Communication 